\title{
ZnO NANORODS FORMATION FOR DYE-SENSITIZED SOLAR CELLS APPLICATIONS
}

\author{
Rangga Winantyo ${ }^{1 *}$, Kenji Murakami $^{2}$ \\ ${ }^{1}$ Department Engineering Physics, Faculty of Engineering and Informatics, \\ Universitas Multimedia Nusantara, Jl. Scientia Boulevard, Gading Serpong, Tangerang, \\ Banten 15811, Indonesia \\ ${ }^{2}$ Graduated School of Integrated Science and Technology \\ Shizuoka University, 5-1 Johoku 3-chome, Naka-ku, Hamamatsu 432-8011, Japan
}

(Received: February 2017 / Revised: May 2017 / Accepted: November 2017)

\begin{abstract}
Different morphologies of zinc oxide $(\mathrm{ZnO})$ can be obtained through various synthesizing methods, such as that of the water bath. By synthesizing under various conditions, different $\mathrm{ZnO}$ morphologies can be seen as the result of the water bath method. Replacing $\mathrm{ZnO}$ nanoparticles with vertically aligned $\mathrm{ZnO}$ nanorods results in a much higher energy conversion efficiency. Yet vertically aligned nanorods can only be grown through difficult and expensive methods. Several researchers have studied the growth of one-dimensional (1D) nanorods on homogeneous film with various growth conditions. However, there has been little in the way of research on $\mathrm{ZnO}$ nanorods grown on $\mathrm{ZnO}$ seed layers using the water bath method. In this research, vertically aligned nanorods with an optimum size ratio were formed through a simple water bath method. This method reveals that the $\mathrm{ZnO}$ nanorods are well aligned and grown with a high density and uniformity on the substrate. Their X-ray diffraction patterns reveal that the nanorods are grow in the [001] direction. The density, diameter, and length of the $\mathrm{ZnO}$ nanorods can be altered by changing the growing condition. All of the samples were characterized using a scanning electron microscope, X-ray diffraction, and micro Raman spectroscopy. To investigate crystal growth, zinc nitrate and zinc acetate were used when preparing the solution. The results demonstrate that the morphology and alignment of $\mathrm{ZnO}$ nanorods are determined by the precursor's type and deposition time.
\end{abstract}

Keywords: DSSC; Nanorods; Nanostructure; One-dimensional; Thin film; Water bath; ZnO

\section{INTRODUCTION}

Previously, in 1991, Grätzel and Brian introduced a solar cell that used a combination of organic semiconductor materials with inorganic semiconductors known as dye-sensitized solar cells (DSSC). The most obvious advantage of DSSC application is the potential it offers for a simple fabrication process that does not require the use of a sophisticated and expensive device, thus permitting more affordable manufacturing costs.

There are many ways to increase the performance of DSSCs. One such method is by increasing the electron transport rate, with one-dimensional nanorods being one of the solutions by which this can be achieved (Unalan et al., 2008). Growing vertically aligned nanorods presents the possibility of increasing the electron transport rate. One important element of growing vertically

\footnotetext{
*Corresponding author's email: rangga.winantyo@umn.ac.id, Tel: +62-21-5422-0808, Fax: +62-21-5422-0800 Permalink/DOI: https://doi.org/10.14716/ijtech.v8i8.733
} 
aligned nanorods is the seed layer (Huang et al., 2008). Furthermore, an investigation was carried out to determine the effect of the seed layer on the morphology and behavior growth of $\mathrm{ZnO}$ nanorods, the results of which are discussed in this paper.

There are many methods that can be used for synthesizing $\mathrm{ZnO}$ nanorods, such as the vapor and solution-phase approaches. However, this research focuses primarily on the solution-phase approach. The solution-phase approach is based on zinc nitrate and hexamethlytetra amine using the water bath and hydrothermal methods and can be carried out under relatively low temperature and pressure (Lee et al., 2003; Law et al., 2005; Baxter et al., 2005). Synthesizing $\mathrm{ZnO}$ through the vapor phase requires a high temperature $\left(>450^{\circ} \mathrm{C}\right)$, with this method being capable of producing high-quality single crystals with a high aspect ratio (Ridhuan et al., 2012). Some of the disadvantages of using this method are its limitations in terms of sample uniformity and low product yield. By contrast, the solution method is preferable since it can be carried out at a low temperature $\left(<200^{\circ} \mathrm{C}\right)$. This method also allows the choice of many kinds of substrates, including organic and inorganic substrates (Wu et al., 2007).

Zinc acetate is commonly used as a precursor solution for seed layer deposition. In this experiment, we also tried using zinc acetate as the precursor solution for growing $\mathrm{ZnO}$ nanostructure.

\section{EXPERIMENTAL METHOD}

\subsection{Seed Layer}

2.1.1. Seed layer preparation

The $\mathrm{ZnO}$ seed layer was deposited using the following method. The fluorine-doped tin oxide (FTO) substrate was cleaned with acetone and ethanol for 15 minutes with an ultrasonic cleaner to remove any organic and inorganic contamination. The seed layer solution was made by mixing 0.7 grams of zinc acetate $\left(\mathrm{CH}_{3} \mathrm{COO}\right) 2 \mathrm{Zn} .2 \mathrm{H}_{2} \mathrm{O}$ and 10 drops of methoxyethanol in 20 $\mathrm{mL}$ ethanol under vigorous stirring for 20-30 minutes. First, we mixed zinc acetate with ethanol and stirred it for 10 minutes. After the solution had become milky in color, methoxyethanol was added drop by drop as a stabilizer. During the stirring process, the seed solution was heated to $60^{\circ} \mathrm{C}$ to increase its solubility.

\subsubsection{Seed layer deposition}

Rotation speed, solution viscosity, and spinning duration are parameters that affect the morphology of the thin film. In this experiment, we used 500 RPM for 10 seconds during the spin-up step and 2500 RPM for 1 minute during the spin-off step. Applying a rotation speed of less than 2500 RPM or a spinning duration of less than 1 minute generates a recoil effect because the solution does not completely evaporate.

The seed layer was then annealed at $100^{\circ} \mathrm{C}$ for 10 minutes. These processes form a seed layer with a 15-20 nm thickness. We were able to repeat this process to form multiple layers or to increase the seed layer thickness. Once satisfied with the thickness of the seed layer, the final step was to anneal the substrate at $350^{\circ} \mathrm{C}$ for 1 hour.

During the experimental process, a $0.03 \mathrm{M}$ concentration and an annealing temperature of $300^{\circ} \mathrm{C}$ were used to see the effect on the morphology of seed layer.

\subsection{ZnO Thin Film}

Two different precursor solutions were made; one by mixing $0.03 \mathrm{M}$ zinc acetate and $0.03 \mathrm{M}$ hexamethylenetetramine in $30 \mathrm{ml}$ deionized water, and the other by replacing the zinc acetate with zinc nitrate. The solution was stirred at room temperature for 10 minutes until the color become transparent. A solution that was milky in color had a solution concentration that was too high. By using these precursor solutions, $\mathrm{ZnO}$ nanorods were grown using the following 
methods.

\subsubsection{Hydrothermal}

The $\mathrm{ZnO}$ nanostructure thin film was grown by immersing the FTO substrate, which was already coated in a seed layer, into the precursor solution inside an autoclave. The substrate was arranged inside the autoclave in a vertical position. The hydrothermal process was carried out by putting the autoclave inside a ceramic oven and heating it at $150^{\circ} \mathrm{C}$ for 12 hours. The resulting white thin film on the FTO surface was cleaned to remove excess materials by dipping it into deionized water. The substrate was then kept dry at room temperature for 20 minutes.

\subsubsection{Water bath}

The FTO substrate, which was already coated in a seed layer, was immersed in the precursor solution and kept in a vertical position. The temperature of the water bath was maintained at $85^{\circ} \mathrm{C}$. After keeping the substrate for 2 hours, it was then cleaned with deionized water and dried at room temperature.

\section{RESULTS AND DISCUSSION}

The morphology of thin film image was taken using a Scanning Electron Microscope (JSM$6320 \mathrm{~F}$ FE-SEM) at an accelerating voltage of $20 \mathrm{kV}$. The molecular structure of $\mathrm{ZnO}$ crystal was investigated using a RIGAKU RINT Ultima III X-ray diffractometer through $\mathrm{Cu} \mathrm{Ka}$ radiation $\left(\lambda=1.5418 \AA\right.$ ) in the $2 \theta$ range from $20^{\circ}$ to $50^{\circ}$ at a $2 \% \mathrm{~min}$ scanning speed.

\subsection{Hydrothermal}

After 12 hours' growth, the morphology of ZnO thin film on FTO substrate was observed. Both types of zinc (zinc acetate and zinc nitrate) grew into a nanoflower form. No vertically aligned nanorods can be seen on the surface of the FTO substrate. The nanoflower structures from both types of $\mathrm{ZnO}$ can be seen in Figure 1.
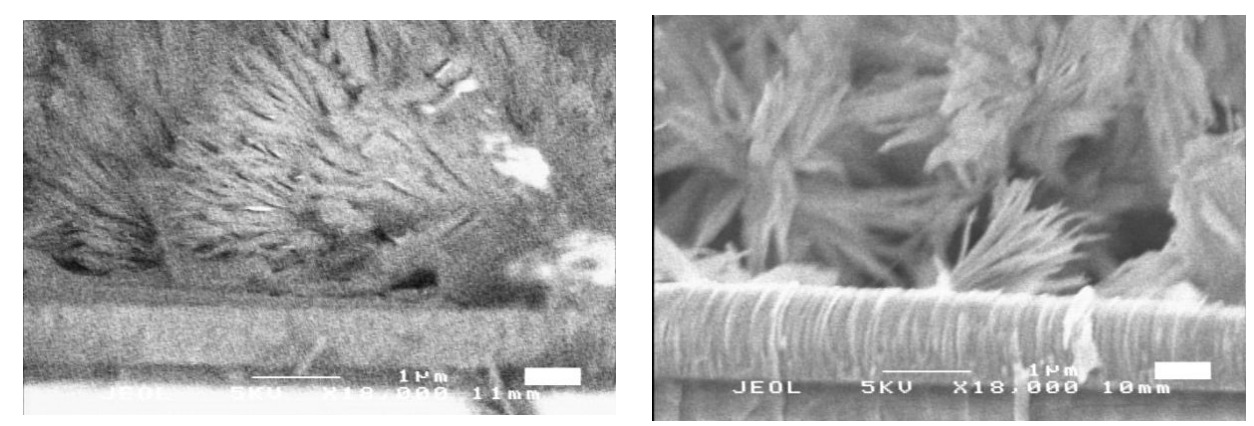

Figure 1 Nanostructures formed through hydrothermal; zinc acetate (left) and zinc nitrate (right)

There was the potential for the $\mathrm{ZnO}$ seed layer to fail during the hydrothermal process due to the high temperature, longer duration process, and high pressure (Sholehah et al., 2017).

\subsection{Water Bath}

In order to provide a comparison with the result obtained from the hydrothermal process, we then sought to produce a seed layer using the water bath method. This method employed a shorter process duration, lower temperature, and no high pressure (Peterson et al., 2004; Liu et al., 2006). The results can be seen in the SEM images below.

Figure 2 contains images of the $\mathrm{ZnO}$ nanorod arrays obtained using the water bath method. The synthesized $\mathrm{ZnO}$ nanorods were well aligned. A significant difference between both $\mathrm{ZnO}$ types was the length of the nanorods. Using zinc acetate, we were able to synthesize vertically aligned nanorods of length for five times longer than nanorods synthesized through zinc nitrate. 

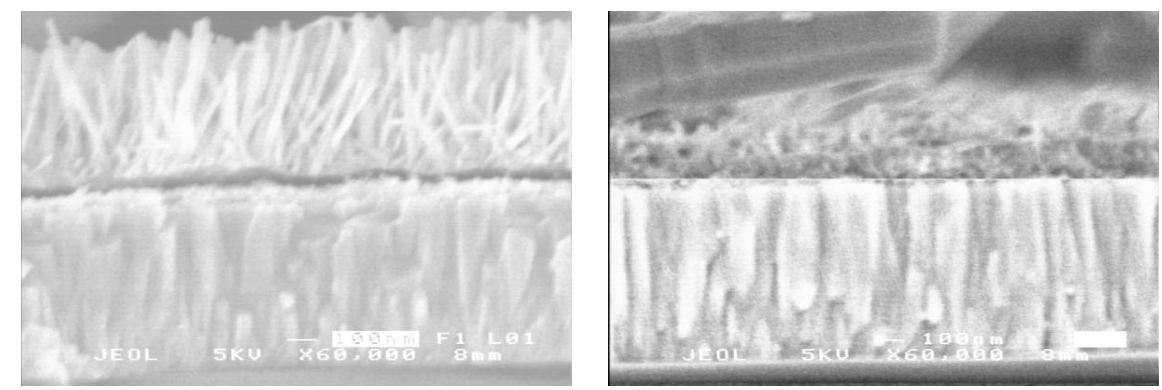

Figure 2 Nanostructures formed through water bath; zinc acetate (left) and zinc nitrate (right)

This could mean that the reaction time of zinc nitrate is less than that of zinc acetate (Penn et al., 2001; Oskam et al., 2003; Yamabi et al., 2005). There is the possibility of synthesizing longer nanorods from zinc nitrate through the application of a longer duration process (Ridhuan et al., 2012).

\subsection{Structural and Photovoltaic Properties}

The XRD patterns of each $\mathrm{ZnO}$ thin layer from the different $\mathrm{ZnO}$ types and different synthesizing methods are shown in Figure 3. From these results, we can see three peaks at $31.8^{\circ}, 34.6^{\circ}$, and $36.9^{\circ}$ that correspond to the [100], [002], and [101] planes of wurtzite structure of $\mathrm{ZnO}$ (Weißenrieder et al., 1997; Srikant et al., 1998; Yubuta et al., 2007). It has been observed that [100] reflection is on the maximum intensity, which indicates that $\mathrm{ZnO}$ films have a preferred orientation in the [100] plane.
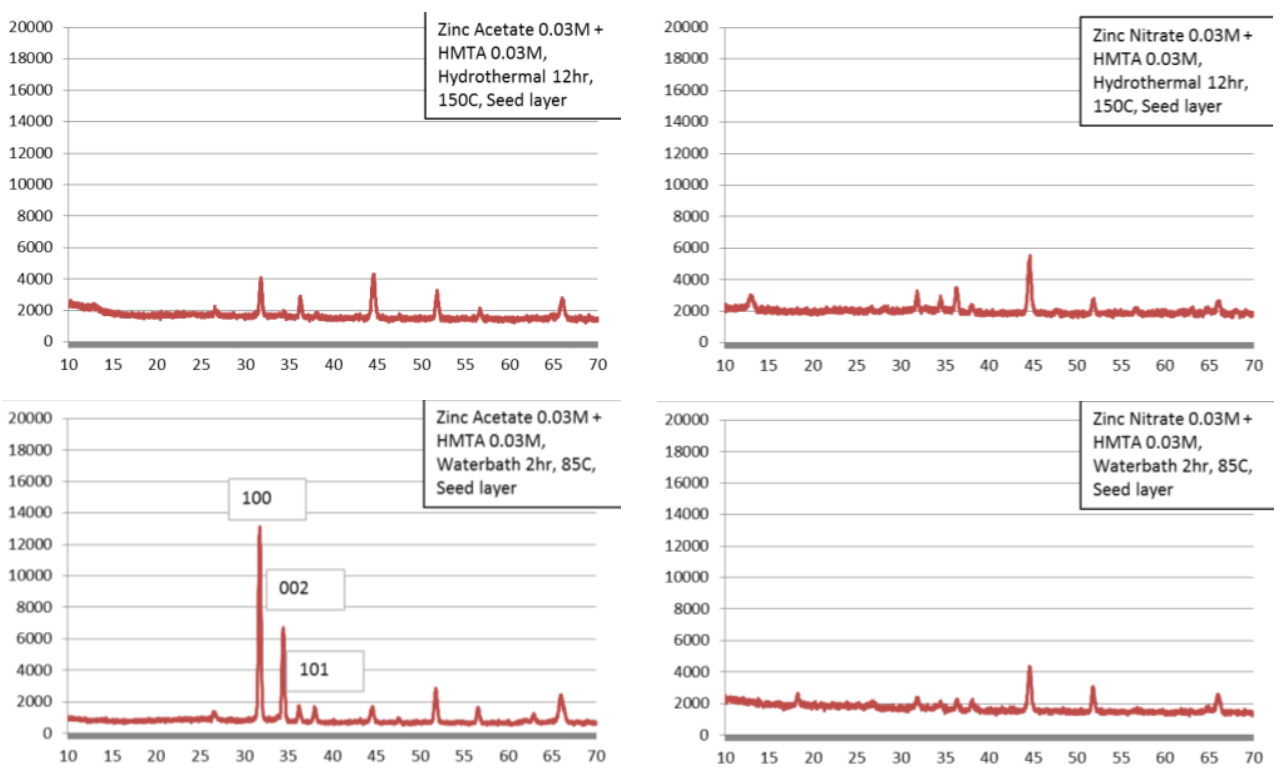

Figure $3 \mathrm{ZnO}$ thin film from different zinc types and synthesizing methods

The highest [100] peaks were obtained from $\mathrm{ZnO}$ thin film synthesized from zinc acetate through the water bath method. This result corresponds to the SEM image in the previous section that shows well-aligned nanorods. Based on the experiment that resulted in the highest peak, a further experiment was carried out to observe the effect of synthesizing duration on the morphology of the seed layer. The durations were varied between 1, 2, and 3 hours. The XRD pattern from this experiment can be seen in Figure 4. 

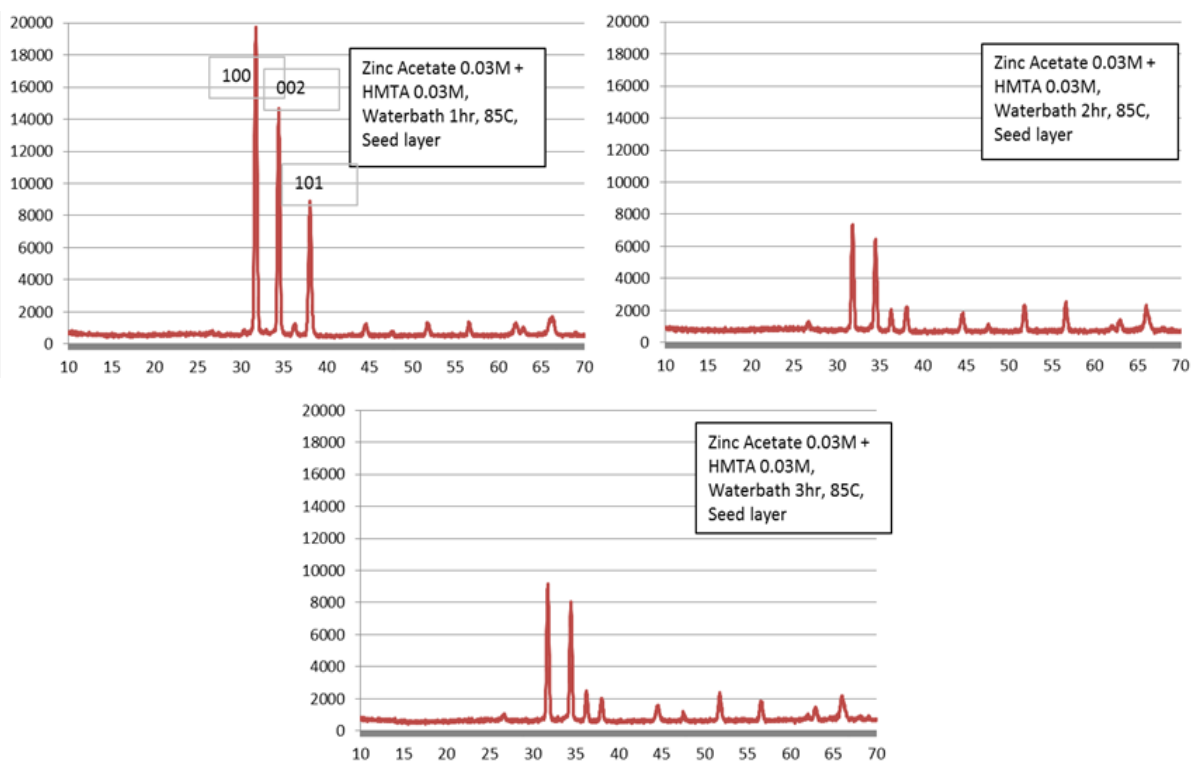

Figure 4 Zinc film XRD patterns from different synthesizing durations

Observing the crystal growth, it can be seen in Figure 5 that the growing process ends after 120 minutes because of insufficient $\mathrm{Zn}$ ion.

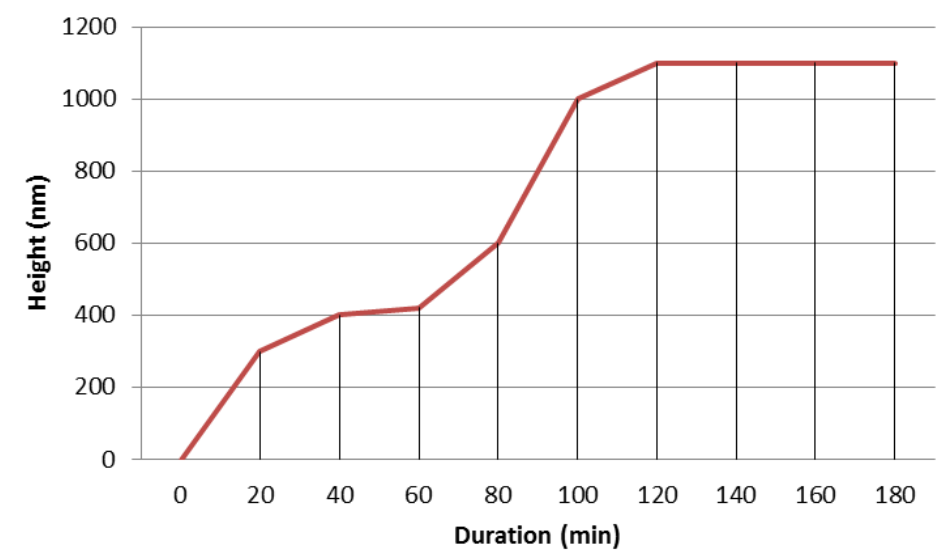

Figure $5 \mathrm{ZnO}$ nanorods growth rate

Both $\mathrm{ZnO}$ films were synthesized with the same parameters, except for the seed layer. Depositing the seed layer on the FTO surface allowed the $\mathrm{ZnO}$ nanorods to grow on the FTO surface, as shown in Figure 6.
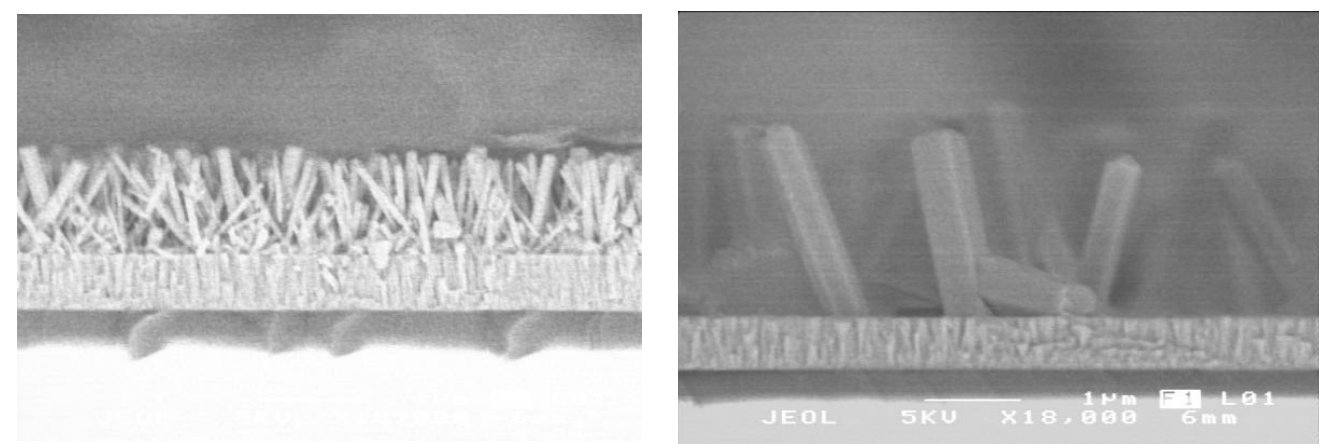

Figure $6 \mathrm{ZnO}$ nanorod arrays with (top) and without (bottom) a seed layer 
From the Transmission Electron Microscope (TEM) image in Figure 7, it can be concluded that the average diameter is in the range $35-55 \mathrm{~nm}$. Fourier transform reveals a symmetrical pattern, which indicates that the nanorods are well crystallized. The spacing between the adjacent lattice planes stacks, as taken from the tips of the nanorods along the growth direction, is around 0.26 $\mathrm{nm}$. This spacing corresponds to the d-spacing of the [0001] planes. This confirms that $\mathrm{ZnO}$ grows with a c-axis orientation.
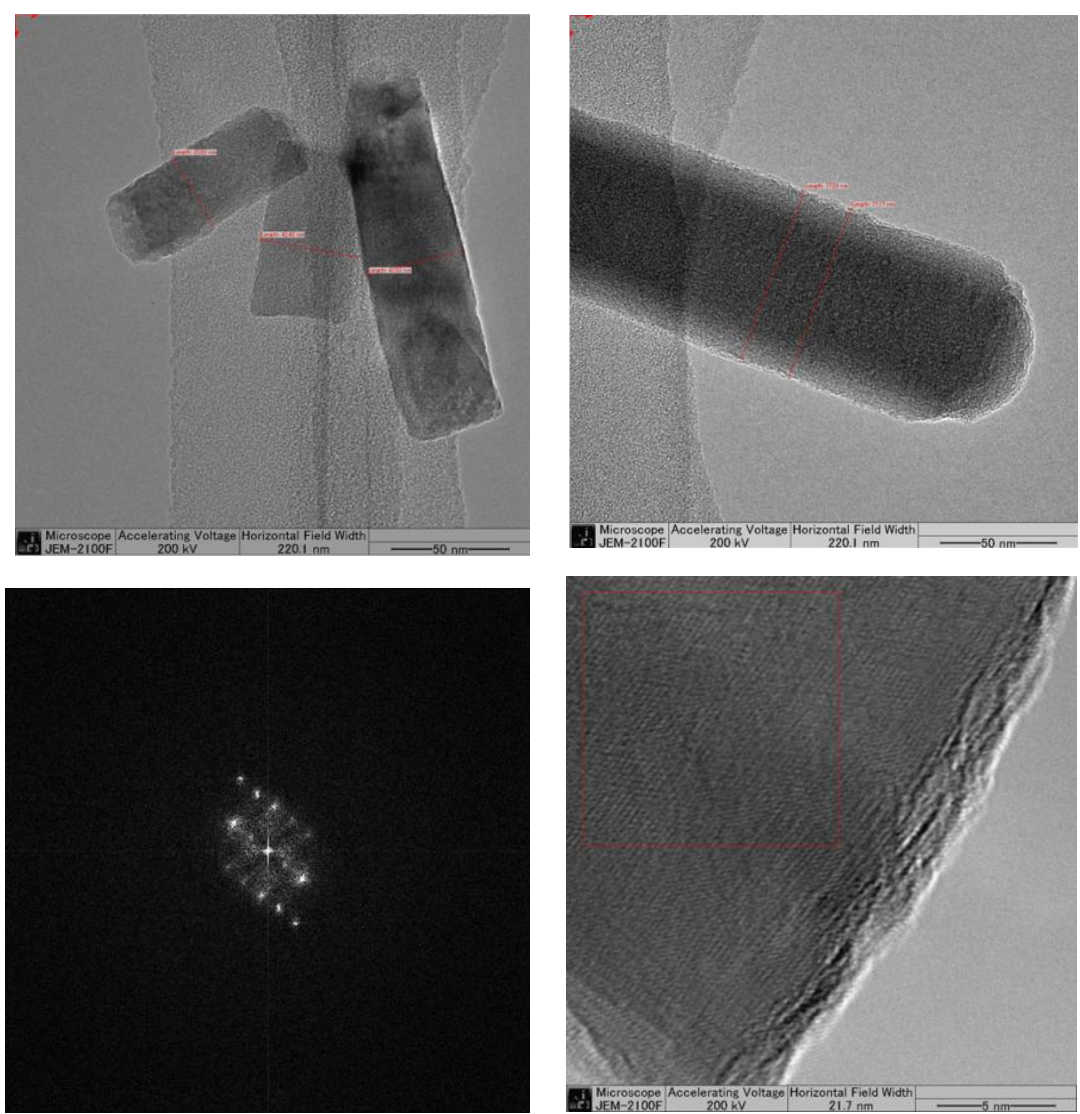

Figure 7 TEM image of $\mathrm{ZnO}$ nanorods

To see the advantages of well-aligned nanorod arrays on photovoltaic application, the I-V characteristic needs to be measured. By comparing 2 different samples (with and without a seed layer) that are synthesized through the same nanorod growing conditions, the effect of aligning the nanorods can be observed. The I-V characteristic curve in Figure 8 shows the effect of a seed layer that gives better alignment of the nanorod arrays.

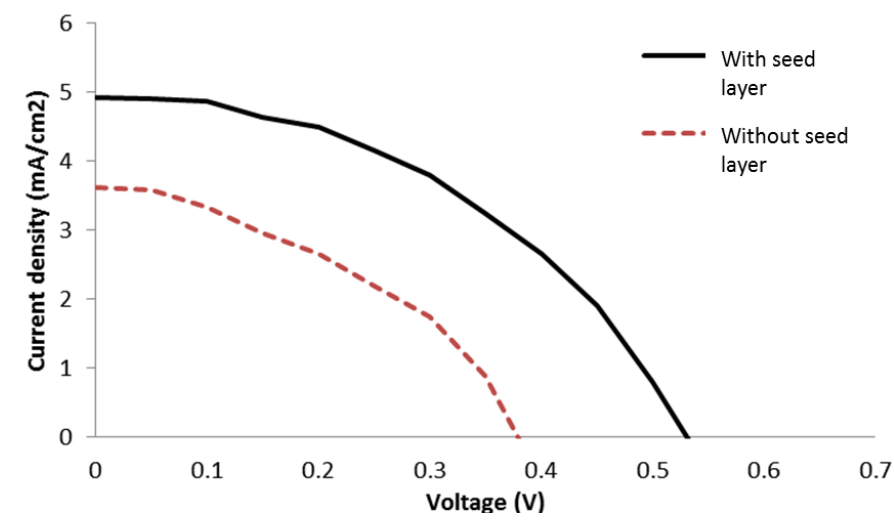

Figure $8 \mathrm{I}-\mathrm{V}$ characteristic curve on vertically aligned nanorods 
The $\mathrm{V}_{\mathrm{oc}}$ was improved by altering the alignment of the nanorods. This may indicate that vertically aligned nanorods can potentially improve the charge transfer rate, thus resulting in an improvement in efficiency from $1.0 \%$ to $1.60 \%$.

\section{CONCLUSION}

Seed layer was confirmed to be successful in growing vertically aligned nanorod arrays. Through I-V characteristic measurement, it has been proved that well-aligned nanorods provide better photovoltaic efficiency. There is a need for better alignment through longer synthesizing duration. This could be done by increasing the density and length of the nanorods. In this case, the optimum concentration of seed layer solution needs to be found. Combinations of zinc acetate dehydrate as a precursor solution and the water bath process have been proved to be an optimum method for synthesizing vertically aligned $\mathrm{ZnO}$ nanorods. Using this combination, $\mathrm{ZnO}$ nanorods can be grown in 2 hours.

\section{ACKNOWLEDGEMENT}

Thank you to the Tropical Renewable Energy Center of Universitas Indonesia, who provided start-up research grants to carry out this research.

\section{REFERENCES}

Baxter, J.B., Aydil, E.S., 2005. Nanowire-based Dye-sensitized Solar Cells. Applied Physics Letters, Volume 86(5), https://doi.org/10.1063/1.1861510

Huang, J-S., Lin, C-F., 2008. Influences of ZnO Sol-gel Thin Film Characteristics on ZnO Nanowire Arrays Prepared at Low Temperature using All Solution-based Processing. Journal of Applied Physics, Volume 103(1), https://doi.org/10.1063/1.2828172

Law, M., Greene, L.E., Johnson, J.C., Saykally, R., Yang, P., 2005. Nanowire Dye-sensitized Solar Cells. Nature Materials, Volume 4(6), pp. 455-459

Lee, J-H., Ko, K-H., Park, B-O., 2003. Electrical and Optical Properties of ZnO Transparent Conducting Films by the Sol-gel Method. Journal of Crystal Growth, Volume 247(1-2), pp. $119-125$

Liu, X., Jin, Z., Bu, S., Zhao, J., Liu, Z., 2006. Growth of ZnO Films with Controlled Morphology by Aqueous Solution Method. Journal of the American Ceramic Society, Volume 89(4), pp. 1226-1231

Oskam, G., Nellore, A., Penn, R.L., Searson, P.C., 2003. The Growth Kinetics of $\mathrm{TiO}_{2}$ Nanoparticles from Titanium(IV) Alkoxide at High Water/titanium Ratio. Journal of Physical Chemistry B, Volume 107(8), pp. 1734-1738

Peterson, R.B., Fields, C.L., Gregg, B.A., 2004. Epitaxial Chemical Deposition of ZnO Nanocolumns from $\mathrm{NaOH}$ Solution. Langmuir, Volume 20(12), pp. 5114-5118

Penn, R.L., Oskam, G., Strathmann, T.J., Searson, P.C., Stone, A.T., Veblen, D.R., 2001. Epitaxial Assembly in Aged Colloids. Journal of Physical Chemistry B, Volume 105(11), pp. 2177-2182

Ridhuan, N.S., Razak, K.A., Lockman, Z., Aziz, A.A., 2012. Structural and Morphology of $\mathrm{ZnO}$ Nanorods Synthesized using ZnO Seeded Growth Hydrothermal Method and Its Properties as UV Sensing. Journal Plos One, Volume 7(11), pp. 1-15

Sholehah, A., Yuwomo, A.H., Sofyan, N., Hudaya, C., Amal, M.I., 2017. Effect of Posthydrothermal Treatments on the Physical Properties of $\mathrm{ZnO}$ Layer Derived from Chemical Bath Deposition. International Journal of Technology, Volume 8(4), pp. 651-661

Srikant V., Clarke, D.R., 1998. On the Optical Band Gap of Zinc Oxide. Journal of Applied Physics, Volume 83(10), pp. 5447-5451 
Unalan, H.E., Hiralal, P., Rupesinghe, N., Dalal, S., Milne, W.I., Amaratunga, G.A.J., 2008. Rapid Synthesis of Aligned Zinc Oxide Nanowires. Nanotechnology, Volume 19(25), pp. $1-5$

Weißenrieder, K-S., M“uller, J., 1997. Conductivity Model for Sputtered ZnO-thin Film Gas Sensors. Thin Solid Films, Volumr 300(1-2), pp. 30-41

Wu, L., Wu, Y., 2007. Synthesis and Optical Characteristic of ZnO Nanorod. Journal of Materials Science, Volume 42(1), pp. 406-408

Yamabi, S., Yahiro, J., Iwai, S., Imai, H., 2005. Formation of Cellular Films Consisting of Wurtzite-type Zinc Oxide Nanosheets by Mediation of Phosphate Anions. Thin Solid Films, Volume 489(1-2), pp. 23-30

Yubuta, K., Sato, T., Nomura, A., Haga, K., Shishido, T., 2007. Structural Characterization of $\mathrm{ZnO}$ Nano-chains Studied by Electron Microscopy. Journal of Alloys and Compounds, Volume 436(1-2), pp. 396-399 